\title{
Multiple optical parameters improvisation for outdoor sport lighting by t-test method
}

\begin{abstract}
The standard lighting design softwares are essentially calculating tools without any optimizing features. Use of these softwares lead to trial \& error based iterative design approach. This however produces a set of interim design solutions consisting of appropriate or inappropriate design cases. In this paper, a statistical method, $t$-test, is successfully applied on these interim design solutions. Hence the list of Determinant Luminaires (DLs) and corresponding Optimized Aiming Angles (OAAs) are identified to enhance multiple optical parameters for the inappropriate design cases.
\end{abstract}

Keywords: Determinant Luminaires (DLs), Optimized Aiming Angles (OAAs), Sports Lighting, t-test.

\section{Introduction}

In outdoor sports lighting designing, the luminaires are mounted around the sports arena to provide an appropriate luminous environment by controlling the brightness of an object and its background, so the object appears clear and sharp to the players, stadium viewers and television viewers. There are standard lighting designing softwares available, like - Calculux, Dialux, Europic, AGI32 etc. for initial simulation of lighting design for any indoor and outdoor application [1, 2] area. However the lighting designing softwares are basically calculating tools only without any optimizing features. It often becomes very difficult to determine the suitable aiming angles [3] for the luminaires to achieve the preferred optical parameters [1, 4] in single attempt. Thus it leads to a 'trial and error' based iterative designing process which primarily depends on the skills of the lighting professional or designer and a pool of interim design solutions get evolved. In this context, t-test $[5,6]$ based approach has been taken to select the Determinant Luminaires (DLs) and corresponding Optimized Aiming Angles (OAAs) from the pool of interim design solutions. The multiple-optical parameters [7-11] e.g., Average Horizontal Illumination $\left(E_{H}\right)$, Average Vertical Illumination $\left(E_{V}\right)$, Horizontal Overall Uniformity $\left(\mathrm{U}_{\mathrm{OH}}=\mathrm{E}_{\mathrm{H}}\right.$ $\left.\min / E_{H}\right)$, Horizontal Transverse Uniformity $\left(U_{1 H}=E_{H-m i n} / E_{H}-\right.$ $\max )$, Vertical Overall Uniformity $\left(\mathrm{U}_{\mathrm{OV}}=\mathrm{E}_{\mathrm{V} \text {-min }} / \mathrm{EV}_{\mathrm{V}}\right)$, Vertical Transverse Uniformity $\left(\mathrm{U}_{1 \mathrm{~V}}=\mathrm{E}_{\mathrm{V} \text {-min }} / \mathrm{E}_{\mathrm{V} \text {-max }}\right)$ are improvised by readjusting DLs with corresponding OAAs both in horizontal \& vertical plane. The improvement of lighting design quality is also evaluated by the measure of Coefficient of Variation $(C V=\sigma / \bar{x})$ [11]. However, CV depends on the values of illuminance throughout the field, meaning $\mathrm{CV}$ is regarded as a good indicator of the overall uniformity. A case study was conducted on Yuvabharati Football Stadium, Kolkata, India to explain and evaluate performance of the t-test based outdoor sports lighting desining application.

\section{Steps for Outdoor Sports Lighting \& Data preparation}

The iterative designing process for any outdoor sports lighting facility can be divided into five basic steps

Step I: $\quad$ Select lighting standards or recommendations in terms of multiple-optical parameters as per Class \& Group of play [2].

Step II: Depending on the recommended values of optical parameters, calculate the approximate quantity of luminaires using Lumen Method [3, 12] for a given sports arena.

Step III: Define luminaire mounting arrangements based on provided data or considering all relevant constrains.

Step IV: $\quad$ Aim the luminaires of $(+\mathrm{X},+\mathrm{Y})$ quadrant [12], towards the field. The luminaires in other quadrans are put into double axis symmetry. Simulation is done for the sports lighting design using any lighting design software.

Step V: Check whether the multiple-optical parameters are matching with the standards recommended values or not.

If it matches, the design is 'appropriate';

Otherwise, the design is 'inappropriate' and the designing procedure starts again from Step IV by reaiming individual luminaires.

However it is difficult to say in how many attempts an appropriate design can be prepared. Thus a pool of interium design solutions gets evolved due to itterative design process. The Yuvabharati Football stadium lighting design is done for thirty times in Calculux [13] by following the above steps. Thus a pool of thrity interim design solutions are prepared, consisting both approproite and inappropriate design cases. There are total 448 numbers of luminaires being used in the designs and each quadrant of the field comprises of 112 luminaires. The $(+\mathrm{X},+\mathrm{Y})$ quadrant luminaires are again sub-divided into 16 different sub-sets. However The luminaires in $(+X,+Y)$ quadrant are symbolized by $\mathrm{L} 1, \mathrm{~L} 2, \ldots, \mathrm{L} 112$ and Table 1 indicates the categorization of luminaires according to 16 subsets [6]. The rows of Table 1 indicates each luminaire set and corresponding luminaires included in that particular set.

Table 1. Sixteen different luminaire sets of Yuvabharati Football Stadium in $(+X,+Y)$ quadrant

\begin{tabular}{|c|c|c|c|c|c|c|c|c|}
\hline Set & \multicolumn{7}{|c|}{ Lumianires in $(+\mathbf{X},+\mathbf{Y})$ quadrant } \\
\hline $\mathbf{1}$ & $\mathrm{L} 1$ & $\mathrm{~L} 2$ & $\mathrm{~L} 3$ & $\mathrm{~L} 4$ & $\mathrm{~L} 5$ & $\mathrm{~L} 6$ & $\mathrm{~L} 7$ & $\mathrm{~L} 8$ \\
\hline $\mathbf{2}$ & $\mathrm{L} 9$ & $\mathrm{~L} 10$ & $\mathrm{~L} 11$ & $\mathrm{~L} 12$ & $\mathrm{~L} 13$ & $\mathrm{~L} 14$ & $\mathrm{~L} 15$ & $\mathrm{~L} 16$ \\
\hline $\mathbf{3}$ & $\mathrm{L} 17$ & $\mathrm{~L} 18$ & $\mathrm{~L} 19$ & $\mathrm{~L} 20$ & $\mathrm{~L} 21$ & $\mathrm{~L} 22$ & & \\
\hline $\mathbf{4}$ & $\mathrm{L} 23$ & $\mathrm{~L} 24$ & $\mathrm{~L} 25$ & $\mathrm{~L} 26$ & $\mathrm{~L} 27$ & $\mathrm{~L} 28$ & & \\
\hline $\mathbf{5}$ & $\mathrm{L} 29$ & $\mathrm{~L} 30$ & $\mathrm{~L} 31$ & $\mathrm{~L} 32$ & $\mathrm{~L} 33$ & $\mathrm{~L} 34$ & & \\
\hline $\mathbf{6}$ & $\mathrm{L} 35$ & $\mathrm{~L} 36$ & $\mathrm{~L} 37$ & $\mathrm{~L} 38$ & $\mathrm{~L} 39$ & $\mathrm{~L} 40$ & & \\
\hline $\mathbf{7}$ & $\mathrm{L} 41$ & $\mathrm{~L} 42$ & $\mathrm{~L} 43$ & $\mathrm{~L} 44$ & $\mathrm{~L} 45$ & $\mathrm{~L} 46$ & & \\
\hline $\mathbf{8}$ & $\mathrm{L} 47$ & $\mathrm{~L} 48$ & $\mathrm{~L} 49$ & $\mathrm{~L} 50$ & $\mathrm{~L} 51$ & $\mathrm{~L} 52$ & & \\
\hline $\mathbf{9}$ & $\mathrm{L} 53$ & $\mathrm{~L} 54$ & $\mathrm{~L} 55$ & $\mathrm{~L} 56$ & $\mathrm{~L} 57$ & $\mathrm{~L} 58$ & $\mathrm{~L} 59$ & $\mathrm{~L} 60$ \\
\hline $\mathbf{1 0}$ & $\mathrm{L} 61$ & $\mathrm{~L} 62$ & $\mathrm{~L} 63$ & $\mathrm{~L} 64$ & $\mathrm{~L} 65$ & $\mathrm{~L} 66$ & $\mathrm{~L} 67$ & $\mathrm{~L} 68$ \\
\hline $\mathbf{1 1}$ & $\mathrm{L} 69$ & $\mathrm{~L} 70$ & $\mathrm{~L} 71$ & $\mathrm{~L} 72$ & $\mathrm{~L} 73$ & $\mathrm{~L} 74$ & $\mathrm{~L} 75$ & $\mathrm{~L} 76$ \\
\hline $\mathbf{1 2}$ & $\mathrm{L} 77$ & $\mathrm{~L} 78$ & $\mathrm{~L} 79$ & $\mathrm{~L} 80$ & $\mathrm{~L} 81$ & $\mathrm{~L} 82$ & $\mathrm{~L} 83$ & $\mathrm{~L} 84$ \\
\hline $\mathbf{1 3}$ & $\mathrm{L} 85$ & $\mathrm{~L} 86$ & $\mathrm{~L} 87$ & $\mathrm{~L} 88$ & $\mathrm{~L} 89$ & $\mathrm{~L} 90$ & $\mathrm{~L} 91$ & $\mathrm{~L} 92$ \\
\hline $\mathbf{1 4}$ & $\mathrm{L} 93$ & $\mathrm{~L} 94$ & $\mathrm{~L} 95$ & $\mathrm{~L} 96$ & $\mathrm{~L} 97$ & $\mathrm{~L} 98$ & $\mathrm{~L} 99$ & $\mathrm{~L} 100$ \\
\hline $\mathbf{1 5}$ & $\mathrm{L} 101$ & $\mathrm{~L} 102$ & $\mathrm{~L} 103$ & $\mathrm{~L} 104$ & $\mathrm{~L} 105$ & $\mathrm{~L} 106$ & & \\
\hline $\mathbf{1 6}$ & $\mathrm{L} 107$ & $\mathrm{~L} 108$ & $\mathrm{~L} 109$ & $\mathrm{~L} 110$ & $\mathrm{~L} 111$ & $\mathrm{~L} 112$ & & \\
\hline
\end{tabular}

The aiming of the luminaires in $(+X,+Y)$ quadrans of the field are done depending on their beam angle and skills of the designer. However the vertical aiming angles of the luminaires are kept within certain values to avoid light pollution [3, 11]. The horizontal aiming angles of the luminaires are symbolized as $\mathrm{L} 1 \_\mathrm{X}, \mathrm{L} 22_{-} \mathrm{X}, \ldots . ., \mathrm{L} 112 \_\mathrm{X}$ and the vertical aiming angles are symbolized as L1_Y, L2_Y, 
...., L112_Y. In Table 3, sample horizontal \& vertical aiming angles corresponding to two luminaires in $(+X,+Y)$ quadrant for thirteen design cases out of thirty different design cases are shown for Yuvabharati Football Stadium. The quality of the designs are also measured in terms of CV. The sample values of optical parameters, alongwith CV, for 30 interim design cases are presented in Table 3.

Table 2. Luminaires aiming angles in horizontal \& vertical plane for Yuvabharati Football Stadium in $(+X,+Y)$ quadrant for interim designs

\begin{tabular}{|c|c|c|c|c|c|}
\hline $\begin{array}{l}\text { Design } \\
\text { Case }\end{array}$ & L1_X ( $\left.{ }^{0}\right)$ & L1_Y( $\left.{ }^{0}\right)$ & - & L112_X $\left(^{0}\right)$ & L112_Y $\left(^{0}\right)$ \\
\hline 1 & 49.4 & 68.7 & - & 93.9 & 59.7 \\
\hline 2 & 51.8 & 71 & - & 93.9 & 59.7 \\
\hline 3 & 49.4 & 68.7 & - & 84.9 & 59.7 \\
\hline 4 & 49.4 & 68.7 & - & 93.9 & 59.7 \\
\hline 5 & 49.4 & 68.7 & - & 93.9 & 59.7 \\
\hline- & - & - & - & - & - \\
\hline 10 & 51.1 & 69.1 & - & 93.9 & 59.7 \\
\hline 11 & 61.6 & 70.4 & - & 82.5 & 53.4 \\
\hline 12 & 41.5 & 45 & - & 97.7 & 49.1 \\
\hline 13 & 49.4 & 78.2 & - & 93.9 & 59.7 \\
\hline- & - & - & - & - & - \\
\hline 27 & 27.2 & 61.9 & - & 93.9 & 59.7 \\
\hline 28 & 45 & 61.2 & - & 93 & 59 \\
\hline 29 & 49 & 68.7 & - & 84.2 & 59.7 \\
\hline 30 & 50.3 & 68.2 & - & 90.5 & 58.3 \\
\hline
\end{tabular}

Table 3. Simulated results of Optical Parameters for Yuvabharati Football Stadium

\begin{tabular}{|c|c|c|c|c|c|c|c|}
\hline $\begin{array}{c}\text { Design } \\
\text { Case }\end{array}$ & $\mathbf{E}_{\mathbf{H}}$ (lux) & $\mathbf{U}_{\mathbf{0 H}}$ & $\mathbf{U}_{\mathbf{1 H}}$ & $\mathbf{E}_{\mathrm{V}}$ (lux) & $\mathbf{U}_{\mathbf{0 V}}$ & $\mathbf{U}_{\mathbf{1 V}}$ & $\mathbf{C V}$ \\
\hline $\mathbf{1}$ & 3503 & 0.9 & 0.8 & 2803 & 0.8 & 0.7 & 0.01 \\
\hline $\mathbf{2}$ & 3643 & 0.7 & 0.6 & 3016 & 0.7 & 0.5 & 0.03 \\
\hline $\mathbf{3}$ & 3558 & 0.8 & 0.8 & 2915 & 0.8 & 0.6 & 0.02 \\
\hline $\mathbf{4}$ & 3672 & 0.7 & 0.6 & 3029 & 0.7 & 0.6 & 0.02 \\
\hline $\mathbf{5}$ & 3526 & 0.8 & 0.8 & 2842 & 0.8 & 0.6 & 0.01 \\
\hline- & - & - & - & - & - & - & - \\
\hline $\mathbf{1 0}$ & 3642 & 0.7 & 0.6 & 3017 & 0.7 & 0.6 & 0.03 \\
\hline $\mathbf{1 1}$ & 2686 & 0.6 & 0.3 & 1998 & 0.6 & 0.4 & 0.15 \\
\hline $\mathbf{1 2}$ & 2623 & 0.4 & 0.3 & 1695 & 0.3 & 0.2 & 0.08 \\
\hline $\mathbf{1 3}$ & 2691 & 0.6 & 0.5 & 2134 & 0.5 & 0.3 & 0.02 \\
\hline- & - & - & - & - & - & - & - \\
\hline $\mathbf{2 7}$ & 2660 & 0.4 & 0.3 & 2094 & 0.5 & 0.2 & 0.11 \\
\hline $\mathbf{2 8}$ & 3579 & 0.7 & 0.6 & 2718 & 0.7 & 0.5 & 0.03 \\
\hline $\mathbf{2 9}$ & 3606 & 0.8 & 0.8 & 2919 & 0.8 & 0.6 & 0.02 \\
\hline $\mathbf{3 0}$ & 3630 & 0.8 & 0.7 & 2762 & 0.7 & 0.5 & 0.02 \\
\hline
\end{tabular}

\section{Problem Statement}

There are 30 interim design solutions for Yuvabharati Football Stadium. However among these design cases all the designs are not of same quality. Hence according to the preferred reference values of the optical parameters, the interim design cases can be categorised as shown in equation (1).

$$
\text { DesignCase }(n)=\left\{\begin{array}{l}
\text { Appropriate } \\
\mathrm{E}_{\mathrm{H}} \geq 3400 \operatorname{lux} ; \mathrm{U}_{0 \mathrm{H}} \geq 0.7 ; \mathrm{U}_{1 \mathrm{H}} \geq 0.5 ; \\
\mathrm{E}_{\mathrm{V}} \geq 2700 \operatorname{lux} ; \mathrm{U}_{0 \mathrm{~V}} \geq 0.7 ; \mathrm{U}_{1 \mathrm{~V}} \geq 0.5 \\
\text { Inappropriate } \\
\mathrm{E}_{\mathrm{H}}<3400 \operatorname{lux} ; \mathrm{U}_{0 \mathrm{H}}<0.7 ; \mathrm{U}_{1 \mathrm{H}}<0.5 ; \\
\mathrm{E}_{\mathrm{V}}<2700 \operatorname{lux} ; \mathrm{U}_{0 \mathrm{~V}}<0.7 ; \mathrm{U}_{1 \mathrm{~V}}<0.5
\end{array}\right\}
$$

where ' $n$ ' indicates interim design solution number.

Thus from Table 3 it can be obtained that the interim design case no.11 to no.27 are inappropriate designs and rest of the designs are appropriate ones. Again the CV for few inappropriate designs exhibits alarming values $(C V>0.13)$. It is significant to mention here that although same set of luminaires are used for all the interim design solutions but due to improper aiming of few pertinenet luminaires, there is wastage of artificial light and degradation in multiple optical parameters. In this context ttest is applied on these 30 interim design solutions to identify those pertinent luminaires or DLs. Also the OAAs are calculated to improvise the multiple optical parameters and CV. This may lead to convertion of few inappropriate design cases to appropriate ones.

\section{t-test}

The t-test [14-17] is known as Null hypothesis testing [6, $14]$ which utilizes the concept of probability $[6,14]$. The raw data is analyzed to decide whether to 'reject or 'not to reject' null hypothesis $H_{0}$ and for this purpose, 't-test' is used to find the sampling distribution, assuming $H_{0}$ is really true. This decision about rejection or acceptance of $H_{0}$ is based on probability considerations. The observed $t$ value in the sample is generally different from the expected value because of sampling fluctuations. If the difference between them is large, $H_{0}$ is rejected \& if the difference is not large, $H_{0}$ is not rejected and the difference may be considered.

The interim design solutions are the Population and the aiming angles (both horizontal \& vertical) associated with luminaires are the Samples for which the ' $t$ ' values are calculated. It is assumed that a normal distribution exists and the probability of a particular outcome can be identified. If the ' $t$ ' value for a luminaire is measued beyond critical value range, the luminaire is identified as $D L$. The OAAs are also calculated during the ' $t$ ' value calculations process for the interim design solutions.

\section{Application of t-test}

There are 112 numbers of luminaires in $(+X,+Y)$ quadrant of the field which are sub divided into 16 sets. Thus t-test is applied on these 16 sets individually. The algorithm of t-test is hence described to identify the DLs and corresponding OAAs.

Input: Matrix representing horizontal \& vertical aiming angles of the luminaires where each row represents a interim design case no. \& each column represents a luminaire's aiming angles.

Output: List of DLs \& OAAs.

Step 1: State the level of significance of the test $\&$ the corresponding reference t-value.

Step 2: Calculate degree of freedom (d.f.) [6] \& Population mean $\mu$ [6] (Average of the total set of luminaire aiming angle in the matrix).

Step 3: Calculate mean $\bar{x}$, standard deviation $s$ [6] \& standard error [6] for aiming angles of each luminaire.

Step 4: Calculate ' $t$ ' distribution for aiming angles of each luminaire as $t=\frac{\bar{x}-\mu}{s / \sqrt{n-1}}$

Step 5: Determine the boundary conditions using the d.f.

Step 6: If $\&$ the level of significance.

$t \leq$ Boundary values

Null Hypothesis is true. Hence reject the corresponding luminaire.

Else

Null hypothesis is false. Hence reject the population mean $\mu$ and select the corresponding luminaire as $\mathrm{DL}$. End. 
Among 16 luminaire sets, the horizontal aiming angles of Luminaire Set 1 (consisting eight luminaires L1 to L8) is used to describe sample t-test calculation for selecting the DLs. Thus Table 4 is divided into two parts. The first part describes the horizontal aiming angles of luminaires L1_X to $L 8$ $X$ in $(+X,+Y)$ quadrant of the stadium for all interim design solutions. In the next half of Table 4, the t-test calculation is explained for the luminaires and hence DL selection process. According to the algoritm the ' $t$ ' values individual for luminaires are calculated. The critical value [6] for acceptance or rejection is 1.7, according to the probability of $5 \%$. Thus depending on the individual ' $t$ ' values of each luminaires, either the luminaire gets accepted or rejected with respect to range of critical value. Subsequently the last row indicates the total seven accepted luminaires or DLs ( $L 1$ $X$ to $L 3$ X \& L5_X to L8_X). As an example, it can be explained from Table 4 that the ' $t$ ' value (1.53) of luminaire ' $L 4 \_X$ ' is within the range of critical value $( \pm 1.7)$. Thus the horizontal aiming variation of this particular luminaire (L4) does not affect the design optical parameters significantly. Hence this method is used to identify the $D L s$ from the Luminaire Set 1 . Similarly all the DLs for all the sixteen sets of luminaires are identified based on horizontal and vertical aiming angles.

Table 4. Simulated results of Optical Parameters for Yuvabharati Football Stadium

\begin{tabular}{|c|c|c|c|c|c|c|c|}
\hline $\begin{array}{l}\text { Design } \\
\text { Case }\end{array}$ & ${ }_{\left({ }^{0}\right)}^{\text {L1 } X}$ & $\underset{\left(^{(0)}\right.}{\mathrm{L} 2 \mathrm{X}}$ & ${ }_{\left({ }^{0}\right)}^{\text {L3 X }}$ & $\underset{\left(^{(0)}\right.}{\mathrm{Lu} X}$ & - & $\begin{array}{l}\text { L7 } X \\
\left(^{(0)}\right.\end{array}$ & ${ }_{\left({ }^{0}\right)}^{\text {L8 X }}$ \\
\hline 1 & 49.4 & 12.2 & 30.7 & 42.3 & - & 12.6 & 68.1 \\
\hline 2 & 51.8 & 14.5 & 30.7 & 41.7 & - & 14.2 & 65 \\
\hline 3 & 49.4 & 12.2 & 30.7 & 42.3 & - & 14.2 & 68.1 \\
\hline 4 & 49.4 & 14.9 & 35.8 & 44.2 & - & 15.4 & 68.1 \\
\hline- & - & - & - & - & - & - & - \\
\hline 27 & 27.2 & 9.5 & 23.6 & 54 & - & $\begin{array}{l}12.7 \\
\end{array}$ & 69.3 \\
\hline 28 & 45 & 20 & 28 & 34 & - & 14.6 & 70.1 \\
\hline 29 & 49 & 12.4 & 30 & 42 & - & 14 & 68.4 \\
\hline 30 & 50.3 & 13.9 & 26.2 & 42.3 & - & 11 & 67.5 \\
\hline \multicolumn{8}{|c|}{ t-test Calculation } \\
\hline Mean $\left({ }^{0}\right)$ & 49.5 & 13.80 & 29.89 & 41.9 & - & 16.03 & 69.6 \\
\hline STDEV (S) & 9.516 & 7.79 & 9.53 & 12.3 & - & 14.3 & 4.37 \\
\hline $\begin{array}{l}\text { Standard } \\
\text { Error }\end{array}$ & 1.767 & 1.45 & 1.77 & 2.25 & - & 2.66 & 0.81 \\
\hline $\begin{array}{c}\text { Population } \\
\text { Mean }\end{array}$ & \multicolumn{7}{|c|}{38.54} \\
\hline 't' value & 6.20 & -17.1 & -4.9 & 1.53 & - & -8.5 & 38.3 \\
\hline $\begin{array}{c}\text { significanc } \\
\text { e point of } \\
\text { 't' } \\
\text { at } p=0.05\end{array}$ & \multicolumn{7}{|c|}{1.7} \\
\hline $\begin{array}{c}\text { results for } \\
p=0.05\end{array}$ & DL & DL & DL & X & - & DL & DL \\
\hline
\end{tabular}

The DLs are identified from the aspect of their mean aiming angle values as have been calculated for all 30 interim design cases. Thus the DLs are assigned with their mean aiming angles values. These mean aiming angle values are the OAAs. Table 5 \& Table 6 represents chosen DLs and corresponding OAAs for horizontal \& vertical aiming angles respectively.

Table 5. Identified DLs corresponding to horizontal aiming angles and alongwith OAAs for Yuvabharati Football Stadium

\begin{tabular}{|c|c|c|c|c|c|}
\hline Set & Luminaires & $\begin{array}{c}\text { Angle } \\
\text { (0) }\end{array}$ & Set & Luminaires & $\begin{array}{c}\text { Angle } \\
(0)\end{array}$ \\
\hline \multirow{4}{*}{1} & LI_X & 49.5 & \multirow{4}{*}{10} & L61_X & 46.9 \\
\hline & L2_X & 13.8 & & L62_X & 52.9 \\
\hline & L3_X & 29.9 & & L64_X & 36.4 \\
\hline & L5_X & 32.1 & & L65_X & 32.9 \\
\hline
\end{tabular}

\begin{tabular}{|c|c|c|c|c|c|}
\hline & L6_X & 55.4 & & L66_X & 13.2 \\
\hline & L7_X & 16 & & L67_X & 58.1 \\
\hline & L8_X & 69.6 & & L68_X & 63.3 \\
\hline \multirow{8}{*}{2} & L9_X & 37 & \multirow{7}{*}{11} & L69_X & 30.2 \\
\hline & L10_X & 44 & & L70_X & 24.7 \\
\hline & L11_X & 48.3 & & L71_X & 14.2 \\
\hline & L12_X & 53.7 & & L73_X & 41.8 \\
\hline & L13_X & 29 & & L74_X & 70.1 \\
\hline & L14_X & 10.8 & & L75_X & 69.6 \\
\hline & L15X & 54.9 & & L76 X & 17.1 \\
\hline & L16_X & 49.4 & \multirow{8}{*}{12} & L77_X & 58 \\
\hline \multirow{6}{*}{3} & L17_X & 106.3 & & L78_X & 21.8 \\
\hline & L18_X & 123.7 & & L79_X & 66.2 \\
\hline & L19_X & 113.6 & & L80_X & 43.9 \\
\hline & L20_X & 105.7 & & L81_X & 53 \\
\hline & L21_X & 129.1 & & L82_X & 37.4 \\
\hline & L22_X & 129.9 & & L83_X & 57.4 \\
\hline \multirow{5}{*}{4} & L24X & 46.7 & & L84X & 55.1 \\
\hline & L25_X & 107.6 & \multirow{8}{*}{13} & L85_X & 37 \\
\hline & L26_X & 104.3 & & L86_X & 27.9 \\
\hline & L27_X & 112.2 & & L87_X & 40.3 \\
\hline & L28_X & 69.4 & & L88_X & 74 \\
\hline \multirow{6}{*}{5} & L29_X & 107.7 & & L89_X & 17.1 \\
\hline & L30_X & 85.9 & & L90_X & 49.2 \\
\hline & L31_X & 105.3 & & L91X & 55.7 \\
\hline & L32_X & 116.2 & & L92_X & 64.5 \\
\hline & L33_X & 90.5 & \multirow{8}{*}{14} & L93_X & 54.7 \\
\hline & L34_X & 109.2 & & L94_X & 23.7 \\
\hline \multirow{6}{*}{6} & L35_X & 134.5 & & L95_X & 63 \\
\hline & L36_X & 112.2 & & L96_X & 36.7 \\
\hline & L37_X & 122.4 & & L97_X & 52.4 \\
\hline & L38_X & 89.1 & & L98_X & 57.7 \\
\hline & L39_X & 128.2 & & L99_X & 52.1 \\
\hline & L40_X & 108.7 & & L100_X & 26 \\
\hline \multirow{5}{*}{7} & L42_X & 109.1 & \multirow{6}{*}{15} & L101_X & 54.2 \\
\hline & L43_X & 121.7 & & L102_X & 35.5 \\
\hline & L44_X & 80.2 & & L103_X & 54.7 \\
\hline & L45_X & 97.2 & & L104_X & 64.4 \\
\hline & L46_X & 119.9 & & L105_X & 63.3 \\
\hline \multirow{6}{*}{8} & L47_X & 35.7 & & L106_X & 75.3 \\
\hline & L48_48 & 127.5 & \multirow{5}{*}{16} & L107_X & 27.7 \\
\hline & L49_X & 126.3 & & L109_X & 57.2 \\
\hline & L50_X & 133.7 & & L110_X & 37.8 \\
\hline & L51_X & 125.8 & & L111_X & 48.4 \\
\hline & L52_X & 140.3 & & L112_X & 89.5 \\
\hline \multirow{8}{*}{9} & L53_X & 57.7 & & & \\
\hline & L54_X & 17.6 & & & \\
\hline & L55_X & 20.3 & & & \\
\hline & L56_X & 15.2 & & & \\
\hline & L57_X & 78 & & & \\
\hline & L58_X & 68.3 & & & \\
\hline & L59_X & 78.1 & & & \\
\hline & L60_X & 37.2 & & & \\
\hline
\end{tabular}

Table 6. Identified DLs corresponding to vertical aiming angles and alongwith OAAs for Yuvabharati Football Stadium

\begin{tabular}{|c|c|c|c|c|c|}
\hline Set & Luminaires & Angles & Set & Luminaires & Angles \\
\hline \multirow{3}{*}{1} & L2_Y & 73.69 & 8 & L47_Y & 67.06 \\
\hline & L3_Y & 56.78 & \multirow{3}{*}{9} & L54_Y & 75.58 \\
\hline & L4_Y & $\begin{array}{l}73.34 \\
\end{array}$ & & L57_Y & 61.89 \\
\hline \multirow{6}{*}{2} & L9_Y & 63.31 & & L59_Y & 60.11 \\
\hline & $\mathrm{L} 11 \mathrm{Y}$ & 72.31 & \multirow{3}{*}{10} & L63 Y & 59.63 \\
\hline & L12_Y & 62.67 & & L65_Y & 70 \\
\hline & L13 Y Y & 64.01 & & L67 Y & 61.02 \\
\hline & L14_Y & 69.67 & \multirow{2}{*}{11} & L71_Y & 76.37 \\
\hline & L16_Y & 70.42 & & L72_Y & 61.3 \\
\hline
\end{tabular}




\begin{tabular}{|c|c|c|c|c|c|}
\hline \multirow{4}{*}{3} & $\mathrm{~L} 18 \mathrm{Y}$ & 56.21 & & L74_Y & 67.36 \\
\hline & L19_Y & 72.62 & \multirow{4}{*}{12} & L78_Y & 73.14 \\
\hline & L20_Y & 62.07 & & L79_Y & 64.27 \\
\hline & L22 Y & 67.64 & & L81_Y & 72.32 \\
\hline \multirow{4}{*}{4} & L23_Y & 56.87 & & L84_Y & 65.49 \\
\hline & L25_Y & 72.3 & \multirow{5}{*}{13} & L88_Y & 69.28 \\
\hline & L27_Y & 58.3 & & L89_Y & 71.61 \\
\hline & L28_Y & 53.88 & & L90_Y & 66.33 \\
\hline \multirow{5}{*}{5} & L29_Y & 61.49 & & L91_Y & 56.6 \\
\hline & L31_Y & 72.34 & & L92_Y & 58.45 \\
\hline & L32_Y & 70.92 & \multirow{5}{*}{14} & L94_Y & 72.47 \\
\hline & L33_Y & 53.29 & & L95_Y & 66.6 \\
\hline & L34_Y & 74.04 & & L96_Y & 71.96 \\
\hline \multirow{5}{*}{6} & L35_Y & 66.49 & & L97_Y & 64.52 \\
\hline & L37_Y & 58.77 & & L100_Y & 74.53 \\
\hline & L38_Y & 56.29 & \multirow{3}{*}{15} & L101_Y & 71.9 \\
\hline & L39_Y & 69.37 & & L104_Y & 61.45 \\
\hline & L40_Y & 56.79 & & L106_Y & 64.67 \\
\hline \multirow{6}{*}{7} & L41_Y & 56.55 & \multirow{5}{*}{16} & L107_Y & 64.62 \\
\hline & L42_Y & 63.18 & & L108_Y & 55.47 \\
\hline & L43_Y & 57.34 & & L109_Y & 63.67 \\
\hline & L44_Y & 66.31 & & L110_Y & 56.16 \\
\hline & L45_Y & 56.84 & & L111_Y & 64.83 \\
\hline & L46_Y & 64.31 & & & \\
\hline
\end{tabular}

Performance evaluation of t-test based approach

The next phase of approach is the performance evaluation [18] of t-test based outdoor sports lighting designing approach. Performance evaluation tests whether the designed system performs satisfactorily for which it is built. The performance evaluation of t-test based approach is carried out through following three steps :

- First Step is reforming new set of design solutions for inappropriate designs (interim Design Case 11 to 27) where the aiming angles of the DLs are replaced by OAAs in horizontal \& vertical plane and rests of the luminaires kept unaltered.

- Second Step is to redesign Yuvabharati Football stadium with this new sets of aiming angles for the inappropriate design cases and redo the calculations to fetch the optical parameters by Calculux.

- Third Step is to evaluate whether the six optical parameters $\left(E_{\mathrm{H}}, \mathrm{U}_{0 \mathrm{H}}, \mathrm{U}_{1 \mathrm{H}}, \mathrm{E}_{\mathrm{V}}, \mathrm{U}_{0 \mathrm{~V}}, \mathrm{U}_{1 \mathrm{~V}}\right)$ have improved or not for inappropriate designs with respect to initial values. The revised CV values are also compared with the previous results.

The revised and initial values of the optical parameters for the inappropriate design cases are represented in comparative manner through Table 7 . The t-test based approach shows significant improvisation of all six optical parameters. In this process of improvising optical parameters, few inappropriate design solutions are also converted to appropriate ones. As an example from Table 7 , the redesigned optical parameters for design case no.16 are so improvised now that design case no.16 has been converted from inappropriate to appropriate design according to equation 1 .

However, CV is not limited to the outliers or extreme values. It is possible that the field will still have some locations with very high or low illuminance. To some extent, $\mathrm{CV}$ is regarded as a good indicator of the overall uniformity. This may be problematic for players, spectators, or cameras. The guidelines suggest to keeps CV under 0.13 for international sporting zone of FIFA Class $V$ Standard [19]. In t-test based approach, the CV is kept well under recommended value for inappropriate designs as indicated in Table 7.
The performance of t-test based outdoor sports lighting designing approach is further analyzed precisely through

$$
P I=\left(\frac{(P R)_{\mathrm{Revised}}-(P R)_{\mathrm{Pr} \text { evious }}}{(P R)_{\mathrm{Pr} \text { evious }}}\right) \times 100 \%
$$

where 'PI' stands for 'Percentage Improvement' and 'PR' stands for 'Photometric Parameter'.

Table 8 indicates the quantitative improvement of six optical parameters in terms of 'Pl'. At this point, apart from three odd cases, rests of the parameters have been improvised remarkably by this approach.

\section{Conclusion}

Sports lighting designing is a multiple optical parameters optimization approach which is preliminarily dependent on skills of the designer. However this paper illustrates the concept of improvisation of multiple optical parameters through DLs and corresponding OAAs. Hence perticular luminaires of $(+X,+Y)$ quadrant are only to be readjusted with precise horizontal \& vertical aiming angles, instead of all the luminaires. The performance evaluation of this technique is also evident from the PI values where all the six optical parameters have been improved. However on the other way, it can also be pointed out that improper aiming of few pertinent luminaires smudge significant loss of artificial light by degrading design quality.

The noteworthy is improvisation of few inappropriate designs to appropriate ones although almost 95\% luminaires are getting identified as DLs. Hence in future scope of work, Rough Set Theory based approach can be introduced for further reduction in quantity of DLs.

The authors are indebted to Prof.Chandan Mazumdar (Professor Computer Science Department, Jadavpur University) for his helpful discussions and for reviewing the manuscript.

\section{References}

[1] The Society of Light and Lighting. SSL LG04-2009; Sports Lighting.

[2] Illuminating Engineering Society of North America. IESNA Lighting Handbook, Ninth Edition IESNA, 2002.

[3] SIMONS, R.H., BEAN, A.R. 2001. Lighting Engineering Applied Calculations. Architectural Press.

[4] British Standard. BS EN 12193 - 2007; Light \& Lighting Sports lighting.

[5] Bonham S.W, Deardorff D.L, Beichner R.J. Comparison of Student Performance Using Web and Paper-Based Homework in College-Level Physics. Journal of Research in Science Teaching 2003; Vol. 40, No. 10: 1050-1071.

[6] DAS N.G. 2008; Statistical Methods - Combined Edition (Volumes I\&II). Tata McGraw-Hill Education Pvt. Ltd.

[7] Indian Society of Lighting Engineers. Newsletter publication January 2009; Vol. IX No.I: 21-26.

[8] [CIE] International Commission on Illumination. CIE83-1989; Guide for lighting of Sports events for colour television.

[9] [CIE] International Commission on Illumination. CIE169-2005; Practice design guidelines for lighting up of sports events for colour television and filming.

[10] [CIE] International Commission on Illumination. CIE 16x: 2005; Technical Report, Practical Design Guidelines for the lighting of sport event for television and filming.

[11] Kevin W. Houser PE PhD, Minchen Wei \& Michael P. Royer. Illuminance Uniformity of Outdoor Sports Lighting, LEUKOS 2011; Vol. 07, No. 4: $221-235$

[12] Nath D, et al. A Novel Approach on Outdoor Sports Lighting Design Methodology and its Validation by Sensitivity Analysis. CIE Int. Conf. Lighting Quality \& Energy Efficiency, kuala Lumpur, Malaysia, 2014: 392 - 402.

[13] http://www.india.lighting.philips.com/connect/tools_literature/ downloads.wpd 
[14] Moore D, McCabe G. 2006; Introduction to the practice of statistics (4th ed.). New York: Freeman.

[15] Montgomery D, Runger G, and Hubele N. Engineering Statistics. John Wiley \& Sons. New York, 2004, chap 4 \& 5.

[16] Winter de. J.C.F. Using the Student's t-test with extremely small sample sizes. Practical Assessment, Research \& Evaluation Journal 2013; Vol. 18, No. 10: 01-12.

[17] Posten, H. O. 1978; The robustness of the two-sample t-test over the Pearson system. Journal of Statistical Computation and Simulation, 6, 195-311.

[18] KONAR A. 1999. Artificial Intelligence and Soft Computing Behavioural and Cognitive Modeling of Human Brain (page no.612).London. CRC.

[19] Fédération Internationale de Football Association (FIFA), Chapter 9, 2011.

\section{Authors}

Author: Dipayan Nath, Department of Electrical Engineering, Future Institute of Engineering \& management Sonarpur Station Road, Kolkata - 700 150; Jadavpur University, Kolkata - 700 032; West Bengal, INDIA, e-mail: dipayan nath@yahoo.co.in; dipayan.nath@gmail.com.

Author: Prof. (Dr.) Saswati Mazumdar, Department of Electrical Engineering, Jadavpur University, Kolkata - 700 032; West Bengal, INDIA, e-mail: saswati.mazumdar@gmail.com.

Author: Sudeshna Mukhopadhyay, Philips Lighting Academy, Philips Electronics Pvt. Ltd., New Delhi, INDIA, e-mail: sudeshna.mukhopadhyay@philips.com

Table 7. Comparison of simulated results of multiple optical parameters between Initial design solutions \& t-test based design solutions for inappropriate design solutions of Yuvabharati Football Stadium

\begin{tabular}{|c|c|c|c|c|c|c|c|c|c|c|c|c|c|c|}
\hline $\begin{array}{l}\text { Design } \\
\text { Cases }\end{array}$ & $\begin{array}{c}E_{H} \\
\text { (Lux) }\end{array}$ & $\begin{array}{c}\mathrm{E}_{\mathrm{H}} \\
\text { (Lux) } \\
\text { (New) }\end{array}$ & $\mathrm{U}_{0 \mathrm{H}}$ & $\begin{array}{c}\mathrm{U}_{\mathrm{OH}} \\
(\mathrm{New})\end{array}$ & $U_{1 \mathrm{H}}$ & $\begin{array}{c}\mathbf{U}_{1 \mathrm{H}} \\
(\mathrm{New})\end{array}$ & $\begin{array}{c}\text { Ev }_{\mathrm{v}} \\
\text { (Lux) }\end{array}$ & $\begin{array}{c}\mathrm{E}_{\mathrm{v}} \\
\text { (Lux) } \\
\text { (New) }\end{array}$ & $U_{0 v}$ & $\begin{array}{c}\mathbf{U}_{\mathrm{ov}} \\
(\mathrm{New})\end{array}$ & $U_{1 \mathrm{v}}$ & $\begin{array}{c}\mathbf{U}_{1 \mathrm{v}} \\
(\mathrm{New})\end{array}$ & CV & $\begin{array}{c}\text { CV } \\
\text { (New) }\end{array}$ \\
\hline 11 & 2686 & 3570 & 0.6 & 0.7 & 0.3 & 0.5 & 1998 & 2786 & 0.6 & 0.6 & 0.4 & 0.4 & 0.15 & 0.03 \\
\hline 12 & 2623 & 3665 & 0.4 & 0.6 & 0.3 & 0.4 & 1695 & 2667 & 0.3 & 0.5 & 0.2 & 0.3 & 0.08 & 0.03 \\
\hline 13 & 2691 & 3105 & 0.6 & 0.8 & 0.4 & 0.6 & 2134 & 2409 & 0.5 & 0.5 & 0.3 & 0.4 & 0.02 & 0.02 \\
\hline 14 & 2694 & 3526 & 0.6 & 0.6 & 0.3 & 0.4 & 1832 & 2510 & 0.6 & 0.6 & 0.3 & 0.3 & 0.05 & 0.03 \\
\hline 15 & 2674 & 3533 & 0.4 & 0.5 & 0.2 & 0.3 & 1762 & 2528 & 0.4 & 0.6 & 0.2 & 0.3 & 0.07 & 0.05 \\
\hline 16 & 2670 & 3453 & 0.6 & 0.7 & 0.4 & 0.5 & 2395 & 2924 & 0.5 & 0.7 & 0.2 & 0.5 & 0.06 & 0.03 \\
\hline 17 & 2614 & 3411 & 0.6 & 0.7 & 0.3 & 0.5 & 2401 & 2810 & 0.6 & 0.8 & 0.4 & 0.5 & 0.06 & 0.03 \\
\hline 18 & 2687 & 3409 & 0.6 & 0.7 & 0.3 & 0.5 & 2535 & 2913 & 0.6 & 0.7 & 0.4 & 0.5 & 0.09 & 0.03 \\
\hline 19 & 2694 & 3285 & 0.5 & 0.7 & 0.4 & 0.5 & 2764 & 2940 & 0.5 & 0.7 & 0.4 & 0.5 & 0.09 & 0.02 \\
\hline 20 & 2660 & 3310 & 0.5 & 0.6 & 0.3 & 0.4 & 2372 & 2793 & 0.5 & 0.6 & 0.3 & 0.4 & 0.12 & 0.04 \\
\hline 21 & 2658 & 3224 & 0.5 & 0.7 & 0.4 & 0.5 & 2774 & 2817 & 0.5 & 0.7 & 0.3 & 0.5 & 0.03 & 0.04 \\
\hline 22 & 2693 & 3433 & 0.5 & 0.7 & 0.3 & 0.5 & 2225 & 2903 & 0.5 & 0.7 & 0.3 & 0.5 & 0.1 & 0.03 \\
\hline 23 & 2090 & 2834 & 0.6 & 0.7 & 0.4 & 0.5 & 2160 & 2288 & 0.5 & 0.4 & 0.3 & 0.2 & 0.03 & 0.02 \\
\hline 24 & 2650 & 3514 & 0.5 & 0.5 & 0.2 & 0.3 & 2089 & 2720 & 0.5 & 0.6 & 0.3 & 0.4 & 0.1 & 0.04 \\
\hline 25 & 2644 & 3574 & 0.6 & 0.7 & 0.3 & 0.5 & 1978 & 2811 & 0.5 & 0.6 & 0.3 & 0.4 & 0.16 & 0.04 \\
\hline 26 & 2656 & 3572 & 0.5 & 0.8 & 0.3 & 0.5 & 2048 & 2850 & 0.6 & 0.7 & 0.3 & 0.5 & 0.13 & 0.07 \\
\hline 27 & 2660 & 3485 & 0.4 & 0.7 & 0.2 & 0.6 & 2094 & 2647 & 0.5 & 0.5 & 0.2 & 0.4 & 0.11 & 0.02 \\
\hline
\end{tabular}

Table 8. Percentage Improvement (PI) of multiple Optical Parameters by the t-test based solution over Initial Design Solutions for Yuvabharati Football Stadium

\begin{tabular}{|c|c|c|c|c|c|c|}
\hline $\begin{array}{l}\text { Design } \\
\text { Cases }\end{array}$ & $\begin{array}{c}\text { \% Increase } \\
\mathrm{E}_{\mathrm{H}}\end{array}$ & $\begin{array}{c}\text { \% Increase } \\
\mathbf{U}_{O H}\end{array}$ & $\begin{array}{c}\text { \% Increase } \\
U_{1 \mathrm{H}}\end{array}$ & $\begin{array}{c}\text { \% Increase } \\
E_{v}\end{array}$ & $\begin{array}{c}\text { \% Increase } \\
\mathbf{U}_{0 v}\end{array}$ & $\begin{array}{c}\text { \% Increase } \\
U_{1 \mathrm{~V}}\end{array}$ \\
\hline 11 & 32.91 & 9.84 & 58.06 & 39.44 & 7.14 & 8.57 \\
\hline 12 & 39.73 & 37.50 & 60.00 & 57.35 & 55.17 & 73.33 \\
\hline 13 & 15.38 & 25.40 & 47.50 & 12.89 & 8.33 & 24.14 \\
\hline 14 & 30.88 & -1.72 & 14.71 & 37.01 & 1.79 & 13.33 \\
\hline 15 & 32.12 & 37.14 & 70.00 & 43.47 & 29.55 & 50.00 \\
\hline 16 & 29.33 & 11.11 & 33.33 & 22.09 & 32.08 & 87.50 \\
\hline 17 & 30.49 & 25.45 & 58.06 & 17.03 & 25.81 & 47.22 \\
\hline 18 & 26.87 & 11.67 & 47.06 & 14.91 & 6.25 & 21.95 \\
\hline 19 & 21.94 & 29.63 & 51.43 & 6.37 & 31.48 & 28.21 \\
\hline 20 & 24.44 & 17.02 & 56.00 & 17.75 & 22.00 & 33.33 \\
\hline 21 & 21.29 & 20.37 & 36.11 & 1.55 & 30.77 & 53.33 \\
\hline 22 & 27.48 & 40.00 & 73.08 & 30.47 & 32.08 & 85.19 \\
\hline 23 & 35.60 & 3.13 & 25.00 & 5.93 & -17.02 & -28.13 \\
\hline 24 & 32.60 & 8.89 & 29.17 & 30.21 & 9.43 & 38.46 \\
\hline 25 & 35.17 & 17.74 & 70.97 & 42.11 & 9.43 & 12.12 \\
\hline 26 & 34.49 & 46.15 & 96.00 & 39.16 & 11.29 & 72.41 \\
\hline 27 & 31.02 & 72.09 & 139.13 & 26.41 & 12.77 & 45.83 \\
\hline
\end{tabular}

